\title{
Studies on Ciliary Dyskinesia Factor in Cystic Fibrosis. II. Short Term Leukocyte Gultures and Long Term Lymphoid Lines
}

\author{
James H. Conover ${ }^{[27]}$, Nicholas G. Beratis, Elaine J. Conod, Eugene Ainbender, and Kurt Hirschhorn \\ Division of Medical Genetics, Department of Pediatrics, Mount Sinai School of Medicine of the City University \\ of New York, New York, New York, USA
}

\section{Extract}

The cell-free medium obtained after 48 hour culture of phytohemagglutinin (PHA)stimulated leukocytes of three cystic fibrosis (CF) subjects and two carriers, contained a ciliary dyskinesia factor (CDF) detected by a modified rabbit tracheal bioassay. Positive CDF responses began to be observed in supernates of parallel non-stimulated cultures of leukocytes from these same CF affected and carrier individuals by 72 hours of culture. Cell-free media from leukocyte cultures of four normal donors did not produce a positive CDF response with or without PHA over a period of 6 days.

The cell-free medium of long-term lymphoid lines derived from three $\mathrm{CF}$ affected and four CF carrier subjects demonstrated a positive CDF response, while media from similar lymphoid lines derived from normal subjects contained no CDF. Distinction between homozygous and heterozygous lymphoid lines was not always possible, although there was a tendency of the homozygous lines to give an earlier CDF response than the heterozygous ones. Addition of rabbit anti-human IgG to the CDF positive cell line supernates resulted in the elimination of their ability to elicit a positive CDF response in each instance.

\section{Speculation}

CDF is a manifestation of a normal cellular product which is a small molecule bound to IgG. The resulting complex represents the CDF detected by bioassay. The defect in $\mathrm{CF}$ is in the production or release of a factor inhibiting the GDF. 


\section{INTRODUCTION}

Human lymphocytes treated with PHA undergo morphologic transformation and increased protein synthesis, followed by mitosis $(21,1)$. Concomitant with these phenomena are increases in the total activity of several lysosomal enzymes $(14,19)$, as well as some non-lysosomal enzymes $(19,24)$. Measurement of enzyme activity during stimulation of lymphocytes with PHA has provided a means of detecting inborn errors of metabolism and the identification of heterozygotes. Normals, heterozygotes, and homozygotes have been clearly delineated in both Pompe's disease (deficiency of acid alpha-1, 4glucosidase) (15) and familial lysosomal acid phosphatase disorder (20). In addition, distinction between normals and homozygotes for homocystinuria (cystathionine synthase deficiency) has also been demonstrated (13).

Lymphoid cell lines derived from human peripheral blood have been established in permanent suspension culture (11) from individuals with varied benign (12) and malignant $(7,17)$ lymphoproliferative disorders, as well as normal subjects $(5,10,18)$. In one of these papers (5), the establishment of such lines from $C F$ carriers has been reported. The technique for establishing lymphoid lines was improved in our laboratory by using a combination of PHA stimulation and incubation with Epstein-Barr virus (2).

We have previously demonstrated the relative stability of the diploid chromosomal pattern of the lymphoid lines, as well as a similarity of donor cells and lymphoid cell lines in the synthesis of a va riety of enzymes including the maintenance of their genetic polymorphisms (8). Lymphoid line cells, derived from subjects with Chediak-Higashi syndrome retain the unusual morphologic features observed in the donor (4). Also, lymphoid lines derived from subjects with inborn errors, such as the Lesch-Nyhan syndrome (6), and metachromatic leukodystrophy (MLD) (3) have reflected the enzyme deficiencies characteristic of the cell line donors.

In this paper, we are reporting the production of a ciliary dyskinesia factor (CDF), resembling in its action the serum factor described by Spock (23), by peripheral leukocytes from homozygotes and obligate heterozygotes for $C F$, and by long-term lymphoid cell lines established from $C F$ affected and carrier subjects.

\section{MATERIALS AND METHODS}

Peripheral leukocyte culture. Heparinized peripheral blood was obtained from three patients with $C F$, two obligate heterozygotes, and four healthy donors. In all cases, blood was allowed to sediment by gravity in a syringe until just prior to buffy coat formation. The supernatant plasma rich in white cells was removed through a bent needle and centrifuged at $150 \times \mathrm{KG}$ for 15 minutes. The isolated leukocytes were washed once with the culture medium, re-centrifuged, and then re-suspended in medium. Lymphocytes in each sample were differentially counted in a hemocytometer, but no attempt was made to isolate purified lymphocytes.

Each culture tube contained $1 \times 10^{6}$ lymphocytes in $1 \mathrm{ml}$ of RPMI-1640 medium, supplemented with $10 \%$ fetal calf serum, L-glutamine, penicillin and streptomycin. Two series of tubes were prepared from each subject.
In one series $2 \mu \mathrm{g} / \mathrm{ml}$ of purified PHA, MR68 or 69 (Burroughs-Wellcome), was added, while the other series contained no PHA. All cultures were maintained at $37^{\circ} \mathrm{C}$, and gassed with $5 \% \mathrm{CO}_{2}$. Replicate cultures of both series from each patient were stopped after 24,48 , and 72 hours, and after 6 days of incubation.

Lymphoid cell lines. Long-term lymphoid cell lines from CF patients, CF obligate heterozygotes, and normal subjects have been established in our laboratory. The procedure of establishment included phytohemagglutinin (PHA) stimulation of the lymphocytes and addition of Epstein-Barr virus (EBV) (2). Lymphoid lines were also established without the addition of EBV. Cell lines established with and without the addition of EBV are designated as EBV and NB, respectively. A total of approximately 5-8 weeks were required before a line of cells demonstrated establishment as indicated by the onset of regular cell division (11). After establishment, cell lines were maintained in culture by feeding them once a week with RPMI1640 medium, supplemented with $20 \%$ fetal calf serum, $1 \% 200 \mathrm{mM}$ L-glutamine, penicillin and streptomycin. Seventeen lymphoid.lines were used in this study. The control group consisted of four lines derived from healthy donors 2 from obligate heterozygotes for metachromatic leukocystrophy (MLD), 2 from obligate heterozygotes for homocystinuria, l from a patient with infectious mononucleosis, and 1 from a patient with MLD. Four lines were derived from obligate heterozygotes for $C F$ and 3 from patients with $C F$. Cell lines were allowed to reach a stable population of $1-2 \times 10^{6}$ cells per $\mathrm{ml}$ of culture fluid and $5 \mathrm{ml}$ aliquots of this cell suspension were centrifuged at $150 \times$ G for 15 minutes. The cell pellet was washed once with medium, re-centrifuged and the pellet was resuspended in $10 \mathrm{ml}$ of the culture medium. The cells were cultured in $25 \mathrm{sq}$. $\mathrm{cm}$. tissue-culture plastic flasks (Falcon Plastics) for 48 hours at $37^{\circ} \mathrm{C}$ in the presence of $5 \% \mathrm{CO}_{2}$. Subsequently the cells were removed by centrifugation and the supernate was collected for bioassay. Duplicate cell counts were performed in the heterozygous and homozygous CF lines, and cultures with cell concentrations of $0.5 \times 10^{6}$ cells per $\mathrm{ml}$ of medium were prepared. The cell free media from these cultures were tested for CDF activity after 40,48 , and 66 hours of culture. Each of the cell-free supernates of the CF and carrier lymphoid cell lines was treated with rabbit-anti-human-IgG (Meloy Laboratories, $4.9 \mathrm{mg} / \mathrm{ml}$ initial concentration) in the following manner: $0.9 \mathrm{ml}$ of each supernate + $0.1 \mathrm{ml}$ rabbit anti-human-IgG were incubated at $37^{\circ} \mathrm{C}$ for one hour, and then overnight at $4^{\circ} \mathrm{C}$, centrifuged to remove antigen-antibody complexes, and the resulting supernates were tested for $C D F$ activity by the tracheal bioassay.

Bioassay. The cell-free medium of each culture was assessed for cilioinhibitory properties by using our modification (9) of the Spock bioassay system (23) which utilizes ciliated rabbit tracheal explants. The preliminary screening of tracheal explants, as well as all bioassay microscopy was performed in a $37^{\circ} \mathrm{C}$ warm room. An appropriate border of a ciliated explant was brought into focus within 15 to 30 seconds after the sample to be evaluated was placed on the tracheal tissue on a glass slide, and the ciliary 
reaction was then observed and recorded after three minutes. The reaction was allowed to proceed an additional three minutes, and the results again recorded at six minutes. Samples were assayed individually on at least two separate occasions, being alternately unknown to one of two observers. The time intervals used have been found to be adequate for the detection of the Spock factor in sera of CF patients and obligate heterozygotes (9).

\section{RESULTS}

Peripheral leukocytes. Results of the bioassays performed on the cell-free media of the short term peripheral leukocyte cultures are recorded in Table I, The findings indicate that the PHA-stimulated and non-stimulated leukocytes of normal donors do not produce detectable CDF during the entire culture interval used. However, the PHA-stimulated leukocytes of patients and heterozygotes with CF seem to produce by 48 hours of culture a factor (s) causing ciliary dyskinesia. The ciliary dyskinesia effects began to be observed in non-stimulated cultures from CF homo-and heterozygotes by 72 hours.

Lymphoid cell lines. Results of the bioassays performed on the cell-free media of the established lymphoid cell lines are presented in Table II.

The cell-free media from these lymphoid cells always reflected the presence of the CF gene. Generally, but not consistently, the zygosity of the donor was demonstrated by producing a CDF response in our bioassay with differential incubation with the tracheal explants. All three CF homozygous cell lines produced strongly positive CDF responses after only three minutes. The media from three out of four obligate heterozygote lines did not elicit a CDF response by three minutes, but did produce a strongly positive CDF response after six minutes. In the fourth heterozygous line a positive CDF response was observed by 3 minutes. Moreover, the cellfree media from parallel cultures of CF homo- and heterozygous lines initiated with an approximately equal number of cells, failed to consistently distinguish between CF affected and carrier lines at the culture intervals tested. It should be noted that two of the ten control lines demonstrated a weak three minute $C D F$ response, which developed into a strongly positive CDF response at six minutes. One of these cell line donors was heterozygous for MLD, while the other was heterozygous for homocystinuria. Serum assays on several donors of CF affected and carrier lines, when tested, and on the donors of the two control lines that elicited a positive CDF effect also demonstrated a $C D F$ response by tracheal bioassay.

The incubation of rabbit anti-human-IgG with these cell-free media, resulted in a visible precipitate after overnight exposure at $4^{\circ} \mathrm{C}$ and centrifugation. These media, after treatment with anti-IgG, demonstrated no $C D F$ activity during a six minute assay. The stock solution of rabbit antihuman-IgG also did not demonstrate a positive CDF response when tested alone.

\section{DISCUSSION}

The data from the short term leukocyte cultures suggest that PHA stimulates the lymphocytes of $\mathrm{CF}$ patients and heterozygotes to produce or release CDF. The production of CDF by non-stimulated cells in longer culture periods probably reflects the "spontaneous" activation of cultured lymphocytes sometimes observed after three days of culture in the presence of fetal calf serum, or a slower rate of production or release by non-stimulated cells. Moreover, these data indicate that the leukocytes can produce CDF, which is considered characteristic of serum from CF patients and carriers. Another similarity to the studies with serum CDF is that it was not possible to distinguish CF homozygotes from heterozygotes.

The lymphoid cell lines appear to reflect the genetic status of their respective donors, by releasing $C D F$ in the culture medium. The positive response elicited by the media of one each of the MLD and homocystinuria heterozygote lines can not be explained at this time. The positive serum assay found in these two donors may indicate that they are heterozygotes for $C F$, a not unlikely possibility in view of the high gene frequency in the general population. The fact that no clear distinction could be demonstrated in the CDF activity between lymphoid lines derived from patients and obligate heterozygotes for $\mathrm{CF}$, by no means indicates that homozygous and heterozygous lines are producing or releasing $C D F$ at the same rate. Even in the experiments where cell counts were performed and cultures started with approximately the same number and concentration of cells, the different growth rate of the lines could explain the inability to distinguish consistently between homozygous and heterozygous lines for CF. In any ca'se, even more cell lines of $C F$ affected and carrier individuals would not change the impracticality of this technique as a routine method for distinguishing CF heterozygotes from $C F$ patients. The time interval required for establishment is simply too long. Nevertheless, the lymphoid lines do provide an advantage over other cultured cells, since these essentially permanent cultures can be grown to massive quantities, thereby providing large amounts of material, such as CDF, for future biochemical and physiologic studies. However, short-term purified lymphocyte cultures will perhaps be able to resolve the problem of discrimination between $C F$ homo- and heterozygotes.

It has previously been reported by McCombs and Bowman (16) and Schmoyer, et al. (22), that a substance of molecular weight 60,000 to 150,000 , not dissociable from IgG by separative techniques, contains the CDF activity in serum. Since in our studies, rabbit anti-human-IgG treated samples effectively lost their CDF activity, and since both the long and short-term data reported here involve immunoglobulin producing cells, it is likely that the CDF characteristic of CF sera, peripheral leukocytes, and long-term lymphoid lines is a fraction of IgG or, more likely, a complex of a small molecule with IgG. Whether this activity can exist in association with $\operatorname{Ig} G$ and/or $\operatorname{IgA}$ is currently unknown and under investigation in our laboratory. 


\section{SUMMARY}

PHA-stimulated peripheral leukocytes from homozygotes and obligate heterozygotes for cystic fibrosis(CF) produce a ciliary dyskinesia factor (CDF) as detected by rabbit tracheal bioassay. Non-stimulated CF affected and $C F$ carrier leukocytes produce the $C D F$ at a slower rate. In contrast, both stimulated and non-stimulated leukocytes from normal individuals do not produce such a factor.

Established lymphoid cell lines from CF affected and carrier subjects also produce a CDF as detected by tracheal assay, in contrast to similar cell lines from normal subjects, which do not produce a CDF. Addition of rabbit anti-human-IgG to each of the supernates of the CF affected and carrier cell lines eliminated $C D F$ activity. The CDF characteristic of $C F$ sera, peripheral leukocytes, and long-term lymphoid lines appears to be due to $\operatorname{IgG}$ itself, or a complex of a small molecule with IgG.

\section{REFERENCES and NOTES}

1. Bach, F.H., Hirschhorn, K.: Gamma globulin production by human lymphocytes in vitro. Exp. Cell Res. $32: 592$ (1963).

2. Beratis, N.G., Hirschhorn, K.: Procedure for establishment of longterm lymphoid cell lines by using PHA and HLV in Application of LongTerm Lymphocyte Cultures to Human Genetics, ed. Smith, G.F. and Bloom, A.D., (in press).

3. Beratis, N.G., Aron, A.M., Hirschhorn, K.: Metachromatic leukodystrophy: Detection in blood serum, lymphoid cell lines and bone marrow fibroblasts. Amer. J. Human Genetics 24:15a (1972), (Abstract).

4. Blume, R.S., Glade, P.R., Grolnick, H.R., Chessin, L.N., Haase, A. T., Wolf, S.M.: The Chediak-Higashi Syndrome: Continuous suspension cultures derived from peripheral blood. Blood 33:821 (1969).

5. Broder, S.W., Glade, P.R., Hirschhorn, K.: Establishment of long-term 23. lines from small aliquois of normal lymphocytes. Blood 35:539 (1970).

6. Choi, K.W., Bloom, A. D.: Biochemically marked lymphocytoid lines: Establishment of Lesch-Nyhan cells. Science 170:89 (1970).

7. Clarkson, B., Strife, A., de Harven, E.: Continuous culture of seven new cell lines (SK-L 1 to 7) from patients with acute leukemia. Cancex 20:926 (1967).

8. Conover, J.H., Hathaway, P., Glade, P.R., Hirschhorn, K.: Persistence 26. of phosphoglucomutase (PGM) polymorphism in long-term lymphoid lines. Proc. Soc. Exp. Biol. Med. 133:750 (1970).

9. Conover, J.H., Paciuc, S., Hathaway, P., Bonforte, R.J., Conod, E.J., Hirschhorn, K., Kopel, F.: Studies on ciliary dyskinesia factor in cystic fibrosis. 1. Bioassay and heterozygote detection from serum. Submitted for publication, Ped. Res.

10. Gexbex, P., Monroe, J.H.: Studies on leukocytes growing in continuous culture derived from normal human donors. J. Nat. Cancer Inst. 40:855 (1968).

11. Glade, P.R., Hirschhorn, K,: Products of lymphoid cells in continuous culture. Amer. J. Path. 60:483 (1970).

12. Glade, P. R., Paltrowitz, I. M., Hirschhorn, K.: Lymphoproliferative potential in infectious diesases. Bull. N. Y. Acad. Med, 45:647 (1969).

13. Goldstein, J.L., Campbell, B.K., Gartler, S.M.: Cystathionine synthase activity in human lymphocytes: Induction by phytohemagglutinin. J. Clin. Inve st. 51:1034 (1967).

14. Hirschhorn, R., Hirschhorn, K., Weissmann, G.: Appearance of hydrolase rich granules in human lymphocytes induced by phytohemagglutinin and antigens. Blood 30:84 (1967).

15. Hirschhorn, K., Nadler, H.L., Waithe, W.I., Brown, B.I., Hirschhorn, R.: Pompe's disease: Detection of heterozygotes by lymphocyte stimulation. Science $166: 1632(1969)$.

16. McCombs, M.L., Bowman, B.H.: Rivanol treatment of cystic fibrosis serum: Effect of supernatant upon ciliary action. Clin. Genet. 1:171 (1970).

17. Moore, G.E., Ito, E., Ulrich, K., Sandberg, A.A.: Culture of human leukemia cells. Cancer 19:713 (1966).

18. Moore, G.E., Gerner, R.E., Franklin, H.A.: Culture of normal human leukocytes. J.A.M.A. 199:519 (1967).

19. Nadler, H.L., Dowben, R.M., Hsia, D.Y.Y.: Enzyme changes and polyribosome profiles in phytohemagglutinin stimulated lymphocytes. Blood 34:52 (1969).

20. Nadler, H.L., Egan, T.: Deficiency of lysosomal acid phosphatase. New Engl, J. Med. 282:302 (1970).

21. Nowel1, P.C.: Phytohemagglutinin: An initiator of mitosis in cultures on normal human leukocytes. Cancer Res. 20:462 (1960).

2. Schmoyer, I.R., Fischer, J.F., Brooks, S.P.: Fractionation of oyster cilia inhibitor from cystic fibrosis heterozygote serum. Biochem. Biophys. Res. Comm. 46:1923 (1972).

. Spock, A., Heick, H.M.C., Cress, H., Logan, W.S.: Abnormal serum factor in patients with cystic fibrosis of the pancreas. Pediat. Res. 1:173 (1967).

24. Whitlock, J.P., Cooper, H.L., Gelboin, H.V.: Aryl hydrocarbon (benzopyrene) hydroxylase is stimulated in human 1ymphocytes by mitogens and benz(a)anthracene. Science 177:618 (1972).

25. Dr. E. J. Conod is a recipient of United States Public Health Service Predoctoral Training Grant no. HD00210 in Human Genetics. Dr. K. Hirschhorn was supported in part by United States Public Health Service Grants nos. AM13674 and HD02552, and by Genetics Center Grant no. GM19443. He is Career Scientist I-513 of the Health Research Council of the city of New York.

27. Requests for reprints should be addressed to: James H. Conover, Ph.D., Division of Medical Genetics, Department of Pediatrics, The Mount Sinai School of Medicine, looth St. and 5th Ave., New York, N.Y. 10029 (USA).

28. Accepted for publication January 29, 1973. 
TABLE I. Ciliary dyskinesia activity in media of leukocytes cultured for 1 to 6 days with and without PHA.

\begin{tabular}{|c|c|c|c|c|c|c|c|c|c|c|c|c|c|c|c|c|}
\hline \multirow[t]{3}{*}{ Donor ${ }^{2}$} & \multicolumn{4}{|c|}{24 Hours } & \multicolumn{4}{|c|}{48 Hours } & \multicolumn{4}{|c|}{72 Hours } & \multicolumn{4}{|c|}{6 Days } \\
\hline & \multicolumn{2}{|l|}{ 'PHA } & \multicolumn{2}{|c|}{ No PHA } & \multicolumn{2}{|c|}{ PHA } & \multicolumn{2}{|c|}{ No PHA } & \multicolumn{2}{|c|}{ PHA } & \multicolumn{2}{|c|}{ No PHA } & \multicolumn{2}{|c|}{ PHA } & \multicolumn{2}{|c|}{ No $\mathrm{PHA}$} \\
\hline & $3^{1^{3}}$ & $6^{\prime}$ & $3 \cdot$ & $6^{\prime}$ & $3^{\prime}$ & $6^{\prime}$ & $3^{2}$ & $6^{\prime}$ & $3^{\prime}$ & $6^{\prime}$ & $3^{\prime}$ & $6^{\prime}$ & $3^{\prime}$ & $6^{\prime}$ & $3^{\prime}$ & $6^{\prime}$ \\
\hline$N-1$ & -1 & - & - & - & - & - & - & - & - & - & - & - & - & - & - & - \\
\hline$N-2$ & - & - & - & - & - & - & - & - & - & - & - & - & - & - & - & - \\
\hline$N-3$ & - & - & - & - & - & - & - & - & - & - & - & - & - & - & - & - \\
\hline$N-4$ & - & - & - & - & - & - & - & - & - & - & - & - & - & - & - & - \\
\hline OH-1. & - & \pm & - & - & ++ & ++ & - & - & + & ++ & + & t+ & - & t+ & + & ++ \\
\hline $\mathrm{OH}-2$ & - & - & - & - & + & + & - & - & + & ++ & - & - &.+ & ++ & - & ++ \\
\hline $\mathrm{CF}-1$ & \pm & \pm & - & - & ++ & ++ & - & - & - & ++ & + & ++ & - & + & - & ++ \\
\hline $\mathrm{CF}-2$ & - & - & - & - & ++ & ++ & - & - & + & ++ & + & ++ & - & + & + & t+ \\
\hline $\mathrm{CF}-3$ & - & \pm & - & \pm & + & $+t$ & - & - & ++ & ++ & - & - & + & ++ & + & ++ \\
\hline
\end{tabular}

$1_{-}=$no ciliary dyskinesia

$t=$ slight dyskinesia

$+=$ strong' dyskinesia

$++=$ very marked asynchrony in ciliary beat
$2_{N}=$ normal control subjects

$\mathrm{OH}=$ obligate heterozygote for cystic fibrosis $\mathcal{C F}^{\mathrm{F}}=$ patients with cystic fibrosis

TABLE II. Ciliary dyskinesia activity in media of long-term lymphoid cell lines.

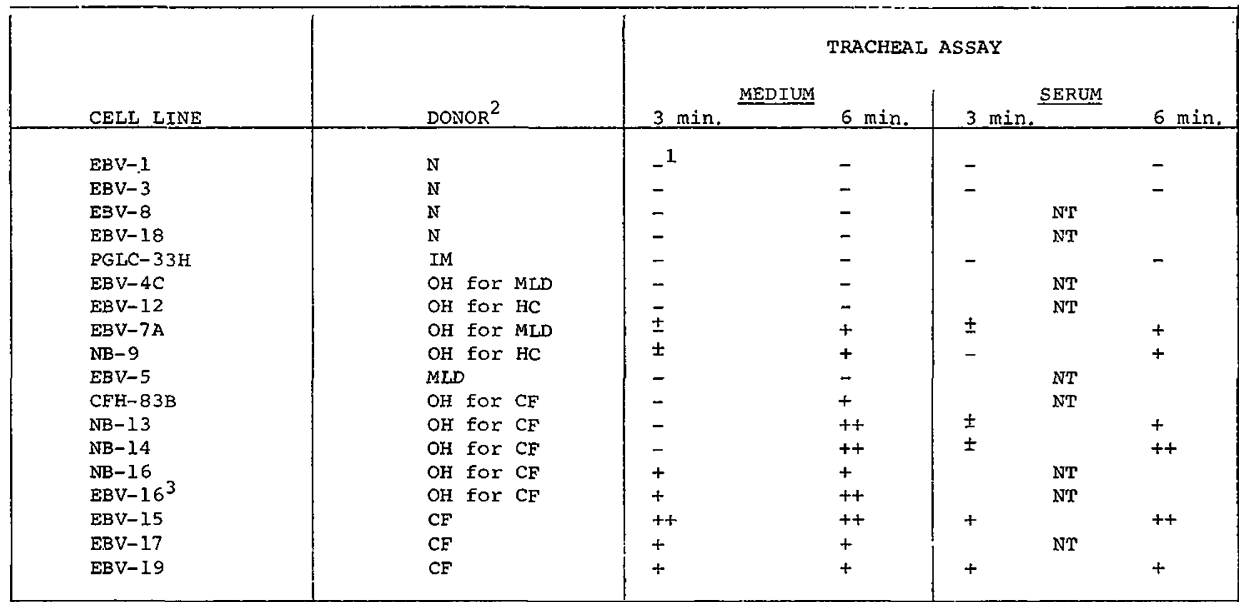

${ }^{1}$ See footnote to Table I for definition of scoring symbols

${ }^{2} \mathrm{~N}=$ normal; IM=infectious mononucleosis: $\mathrm{OH}=\mathrm{Obligate}$ heterozygote; MLD metachromatic leukodystrophy; $\mathrm{NT}=$ not tested; HC=homocystinuria; $\mathrm{CF}=$ cystic fibrosis

${ }^{3}$ Same patient as NB-16, but established with EB virus and PHA while NB-16 was established with PHA alone. 